Volume 9, No.1.5, 2020

International Journal of Advanced Trends in Computer Science and Engineering

Available Online at http://www.warse.org/IJATCSE/static/pdf/file/ijatcse3091.52020.pdf

https://doi.org/10.30534/ijatcse/2020/3091.52020

\title{
Energy Cost Reduction for Telecommunication Towers Using Hybrid Energy Storage
}

\author{
Noor Iziddin Abdullah Ghazali1 ${ }^{1}$,*, Mohd Azri Mohd Izhar ${ }^{1}$, Rudzidatul Akmam Dziyauddin ${ }^{1}$, \\ ${ }^{1}$ Razak Faculty of Technology and Informatics, UTM Kuala Lumpur, \\ Razak Tower, Jalan Sultan Yahya Petra, 54100 Kuala Lumpur, Malaysia, \\ laplace82@gmail.com \& iziddin1982@graduate.utm.my
}

\begin{abstract}
For many mobile phone carriers, the cost to cable electricity to an off-grid tower is simply too expensive. The combination of vast and difficult-to-service areas with the lack of a grid or a reliable power alternative has made the rollout of rural networks essentially unaffordable. Existing works on a good grid and off-grid are not enough to cover the whole spectrum of telecom towers in many countries and continents. The objective of this study is to develop a hybrid energy storage system under energy efficiency initiatives for telecom towers in the poor grid and bad grid scenario to further reduce the capital expenditure (CAPEX) and operational expenditure (OPEX) besides reducing carbon emissions. The present study confirms that by using the micro-grid concept which is a combination of multiple hybrid energy storage can reduce CAPEX and OPEX cost between $9 \%$ to $14 \%$ as compared to the pure valve-regulated lead-acid battery or VRLA battery
\end{abstract}

Key words: lead-acid battery, lithium-ion battery, carbon emission, GSMA

\section{INTRODUCTION}

Green technology in wireless communication is referred to using alternative or renewable energy sources as the power supply on telecom base station sites. Among green technologies that are widely used in the wireless communication, industry are solar photovoltaics (PV), wind turbines and hydrogen or methanol-based fuel cells. The meaning of using green technology to supply power already reach a broader concept by using it to reduce dependency towards diesel generator beside replacing coal fire power plant traditionally. This will reduce the dependencies from fossil fuels to get energy efficiency and renewable energy towards sustainable power supply to power up the telecom base station sites. Eventually, energy efficiency has become an important aspect of a green strategy for telecom operators [1].
Many mobile telecom operators have been using diesel generator (DG) with a battery as part of hybrid solutions. However, this practice increases the dependency of using dirty energy sources to power up the generator based on shorter short-term savings under energy operational expenditure (OPEX) [6-8]. From the Global System for Mobile Communications Association (GSMA) report in [1] on Green Power for Mobile Bi-annual Report, there have many green technologies being deployed from 9000 telecom towers in 2010 to more than 43,000 telecom towers around four years later.

This leads to a study on current methods using diagnosing of lead-acid battery degradation in [2] on the health status and diagnosis of batteries in renewable energy systems. Some of the questions in this study are 100\% depth of discharge (DoD) can be achieved and affect the health of the battery bigger and faster in term of self-discharge issue than that sulfation issue. Despite the improvement in [5] using the solar PV system with energy storage integrated with the electricity grid as mention [9]. However, in [10], a new battery model was proposed for use in time-series performance models of hybrid energy systems.

Other application of hybrid battery using Plug-In-Hybrid Electric Vehicle Charging System to charge the hybrid battery inside the car that may not need internal combustion engine anymore [18]. However, when connected to a hybrid battery consist of lead-acid and/or lithium-ion battery, voltage stability enhancement with distributed generation installation need to look into also [19].

Currently, we have seen energy storage system (ESS) technologies become more widespread and advance. From current research, there are two major points which are to find a new chemical or topology that can store more energy per unit volume and driving the construction costs down so that same energy can be stored for less cost [11]. There have been many factors shown that the lithium-ion battery has more advantage compared to lead-acid battery for stationary storage applications. Based on the comparative study [3], it is shown that the lithium-ion battery can achieve higher efficiency by experiencing more than 5 times the life cycle of a lead-acid battery. In terms of charging and discharging 
factor, the lithium-ion battery is better than the lead-acid battery. The upfront cost of a lead-acid battery is indeed lower than the lithium-ion battery however when it comes to overall operational lifetime, the lithium-ion battery much is better than the lead-acid battery but the cost is too high initially. Due to reason such as higher efficiency, more lifecycle, fast-changing with the lower incremental cost for energy supplied throughout battery lifetime. Its is more suitable for off-grid stationary storage applications. However, for lower temperature locations, we can see lead-acid batteries still the cheaper option specifically in the area of tropical developing countries or cold weather that not required charging in freezing temperatures, the lithium-ion battery would be a good as a long-term investment than lead-acid battery [16].

In this paper, the relationship between cost and hybrid energy storage with energy efficiency is investigated. The contribution would be the initial development of an energy conservation model based on grid availability between 8 hours to 16 hours under the poor grid and bad grid scenarios based on energy-efficient systems such as hybrid energy storage between the lead-acid battery and the lithium-ion battery.

Section 2 reviews related works on hybrid energy storage using batteries. In Section 3, we discuss the costing estimation of hybrid batteries. Our system model on using hybrid battery or energy storage using both lead-acid battery and the lithium-ion battery for the poor grid and bad grid is presented Section 4. Section 5 presents the examined case study and the corresponding results, whereas Section 6 concludes the paper.

\section{RELATED WORKS}

Using batteries as part of energy storage to support the diesel generator and or solar PV coupled with utility grid will reduce further the cost since the solar irradiation rate in Malaysia is better than Germany. However, with the impact of carbon emission on the long term towards the environment, hybrid power system delivers the most energy for 4G/LTE telecom tower. Average annual OPEX savings would be better with hybrid power with the hybrid battery as the main energy storage [10-16]. Following the maintenance and monitoring schedule will increase the lifetime, reliability and durability of the system in the case of Malaysia [12,13].

In the area of the east coast of Malaysia where some of the resorts are in remote islands can be considered as off-grid situation, a stand-alone hybrid energy system using solar, wind, diesel generator looks promising results in the long run. But more study needed for this kind implementation in other parts of the world especially in either poor grid and bad grid conditions [14]. Whereas at East Malaysia, we can see a standalone diesel generator is the best economical but hybrid energy system using renewable energy such as solar PV and energy storage such as batteries can reduce the emissions. An energy storage system where the batteries can store excess energy and reduce storage that can be used during night time can reduce the dependency on diesel generator in the long run [15].

Hybrid energy storage systems using battery energy storage has evolved tremendously for the past two decades especially in the area of car manufacturing either in a fully hybrid electric car or hybrid car that use battery energy storage with internal petrol combustion engine [11]. Other countries like Australia where the cost of utility supply is quite high, they use hybrid graphite solar storage. This will eventually reduce the carbon emission generated from excessive usage from normal utility grid supply [11].

In mobile wireless communications systems, there are many types of backup power supply such as utility supply, renewable energy, energy storage such as lead-acid or lithium-ion batteries. Currently, there are more than $300 \mathrm{MW}$ to $400 \mathrm{MW}$ utility large scale of lithium-ion battery projects already completed worldwide for frequency control, maximum demand plus microgrid integration support for the high power intermittent renewable energy resources [11]. From Table 1, we have seen many types of renewable energy that can enable the agenda of the green cellular base station using mostly batteries as the energy storage with diesel generator (DG) but only Malaysia using renewable energy with batteries and electric grid besides diesel generator for the sake of power supply backup for some critical sites at government and military facilities. The interesting or unique about this research compared to other research-based on hybrid energy storage is to apply hybrid energy storage in the poor grid and bad grid scenarios which are not discussed in another research before. This type of grid availability is between 4 hours to 16 hours, respectively as other research is based on a good grid and off-grid.

Another aspect to look into is the economic dispatch (ED) is an optimization strategy to ensure power systems operate economically. This is by having a multi-objective optimization method to minimize the total generation cost and total system loss simultaneously and find the best adjustment for this economic dispatch problem [20].

There is a large volume of published studies describing the role of an energy storage system in the form of batteries [10-16]. Since there are many types of energy storage with different costs, operation characteristics, and potential applications. To design future proof power systems either for short-term transient operation or long-term generation planning, one needs to understand the energy storage characteristics for long-term generation planning. Based on their architectures, capacities, and operation characteristics, the potential application fields are identified based on poor grid and bad grid due to unavailability study in this type of grid rather than off-grid and on or good grid [12-14]. 


\section{COSTING ESTIMATION OF HYBRID BATTERIES}

The costing of each component was based on the GSMA report in [1] on Green Power for Mobile Bi-annual Report and from other research papers [12-15]. Table 3 shows the breakdown of the cost in USD for different battery types base on the configuration in Table 2. From Table 3, in general, the lithium-ion battery available in the market is based on the size of $50 \mathrm{Ah}$ with $48 \mathrm{~V}$ ratings whereas, for the lead-acid battery, it comes with either $2 \mathrm{~V}$ or $12 \mathrm{~V}$ per module or cell. So a total of 24 of $2 \mathrm{~V}$ module is required to complete $48 \mathrm{~V}$ ratings or a total of 4 of $12 \mathrm{~V}$ module to get a complete $48 \mathrm{~V}$. If there is a need for an additional battery, we add the cost using the battery unit cost mentioned in Table 3. As the battery cost is the overall including also installation cost, cabinet or shelter cost plus additional cabinet/shelter costs if the existing cabinet/shelter cannot accommodate more.

Table 1: Type renewable energy enabling the green cellular base station [17]

\begin{tabular}{|c|c|c|c|c|}
\hline \multirow[b]{2}{*}{ Country } & \multicolumn{4}{|c|}{ Renewable System } \\
\hline & Solar & Wind & $\begin{array}{l}\text { Solar } \\
\text { and } \\
\text { Wind }\end{array}$ & $\begin{array}{l}\text { Solar } \\
\text { and } \\
\text { Fuel } \\
\text { Cell } \\
\end{array}$ \\
\hline Korea & I & & I & \\
\hline Malaysia & l & l & l & \\
\hline India & 1 & I & I & 1 \\
\hline Bangladesh & l & & & \\
\hline Pakistan & I & 1 & 1 & \\
\hline Nigeria & l & & I & \\
\hline Egypt & I & & & \\
\hline Sudan & I & & I & \\
\hline Algeria & & & I & \\
\hline Congo & I & I & 1 & \\
\hline Nepal & I & I & I & I \\
\hline Spain & I & I & I & \\
\hline
\end{tabular}

Table 2: Parameters of the overall configuration

\begin{tabular}{|c|c|c|c|c|}
\hline \multirow{2}{*}{ System } & \multirow{2}{*}{ Parameters } & \multirow{2}{*}{ Value } & \multicolumn{2}{|c|}{ Battery Type } \\
\hline & & & Lithium-Ion & Lead Acid \\
\hline \multirow{7}{*}{ Battery } & Backup hours & hours & 0.32 to 12 & 2 to 16 \\
\hline & $\begin{array}{l}\text { Capacity } \\
\text { required }\end{array}$ & $\mathrm{Ah}$ & 50 to 1000 & 167 to 1333 \\
\hline & Current & Ampere & 83 to 500 & 16 to 133 \\
\hline & $\begin{array}{l}\text { Charging } \\
\text { power }\end{array}$ & $\mathrm{kW}$ & 4.6 to 28 & 0.8 to 6.4 \\
\hline & $\begin{array}{l}\text { Cycles per } \\
\text { day }\end{array}$ & No of cycle & 1 & 2 \\
\hline & $\begin{array}{l}\text { Battery } \\
\text { Cycles }\end{array}$ & nos & 3000 & 1000 \\
\hline & $\begin{array}{l}\text { Battery } \\
\text { lifetime }\end{array}$ & years & 2.7 & 1.3 to 2.7 \\
\hline
\end{tabular}

Table 3: Breakdown of the cost in USD for different battery types

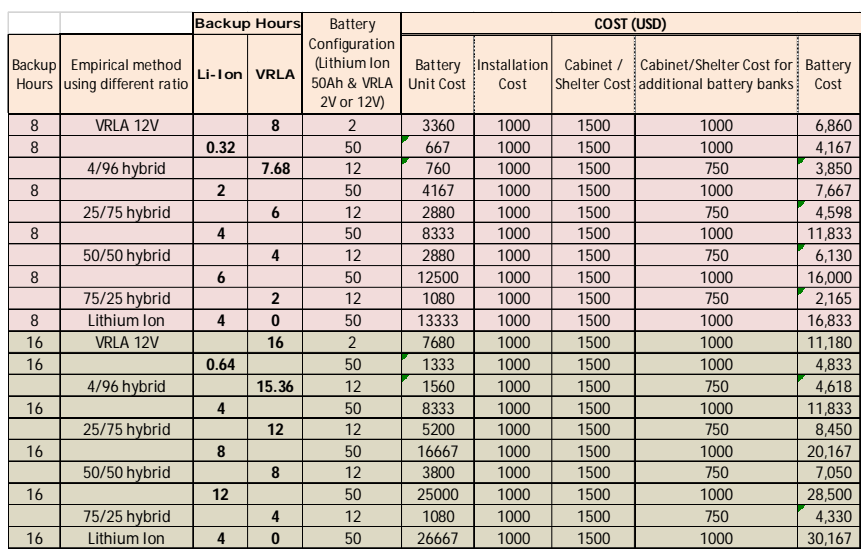

\section{SYSTEM MODEL OF HYBRID BATTERY STORAGE}

To produce an energy optimization model, the input power should be matched the output of the alternating current or AC mains rather than using a direct current (DC) with a diesel generator due to cost impact. The load distribution and switch off voltage of communication power should meet the customer requirements. AC/DC power conversion modules are configured in line with the principle of ' $\mathrm{N}+1$ '. ' $\mathrm{N}$ ' is the number of AC/DC power conversion modules meeting communication load power supply and battery charging. ' 1 ' is the number of redundant power conversion modules based on the system model as in Figure 1.

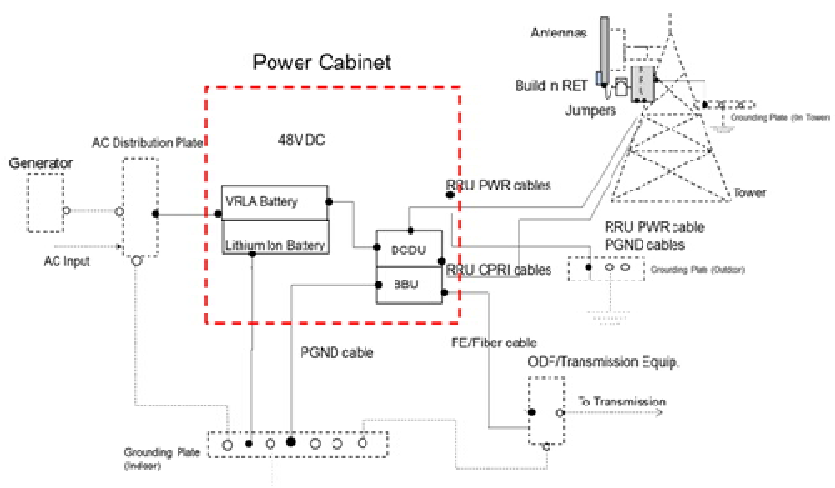

Figure 1: Hybrid energy storage electrical single line diagram

Based on the system model with load at the site is $2000 \mathrm{~W}$, the battery size can be formulated as:

$B=\left(\frac{(I \times H)}{D F}\right) \times C R$ 
From the above equation, we know that $\mathrm{V}$ is for voltage in volt, $\mathrm{I}$ is for current in Ampere, $\mathrm{R}$ is for resistance ohms, $\mathrm{B}$ is the battery capacity, DF based on diversity factor at $0.8, \mathrm{C}$ is the battery current in ampere, CR is battery charge rate and $\mathrm{P}$ is power in Watt. Since voltage (V) is equal to current (I) times resistance $(\mathrm{R})$ and power $(\mathrm{W})$ is equal to voltage $(\mathrm{V})$ times current (I). Therefore, this equation becomes the basis of calculating the battery capacity in Ampere-hours.

Suppose the load power consumption of a base station is $2000 \mathrm{~W}$ by using the lithium-ion battery and the corresponding load current is approximately 41.67A (for simplification, here the $2000 \mathrm{~W}$ power consumption includes the power consumption of the temperature control equipment divided by $48 \mathrm{~V}$ per battery module). The battery capacity is $200 \mathrm{AH}$, and the charging current ratio is $0.5 \mathrm{C}$, and therefore the maximum battery charging current is $83 \mathrm{~A}$. The sum of the load current of the base station is at $6667 \mathrm{~W}$ and the rectifier efficiency is at $96 \%$ where the capacity required is $6944 \mathrm{~W}$. The capacity of a single AC/DC power conversion module is $3000 \mathrm{~W}$, and thus two power conversion modules should be configured. This $\mathrm{s}$ due to the need to comply with the configuration principle of ' $\mathrm{N}+1$ ', three $3000 \mathrm{~W}$ AC/DC power conversion modules are used. This is for an outdoor telecom tower configuration based on Figure 2.

For the lead-acid battery similarly, based on power load consumption of 2000w and correspondingly, 41.67A for the load current. The battery capacity is $200 \mathrm{AH}$, and the charging current ratio is $0.5 \mathrm{C}$, and therefore the maximum battery charging current is 83A. The sum of the load current of the base station is at $6667 \mathrm{~W}$ and the rectifier efficiency is at $96 \%$ where the capacity required is $6944 \mathrm{~W}$. The capacity of a single $\mathrm{AC} / \mathrm{DC}$ power conversion module is $3000 \mathrm{~W}$, and thus two power conversion modules should be used. To comply with the configuration principle of ' $\mathrm{N}+1$ ', three $3000 \mathrm{~W}$ AC/DC power conversion modules are used. The block diagram of the energy system using hybrid energy storage is presented in Figure 2.

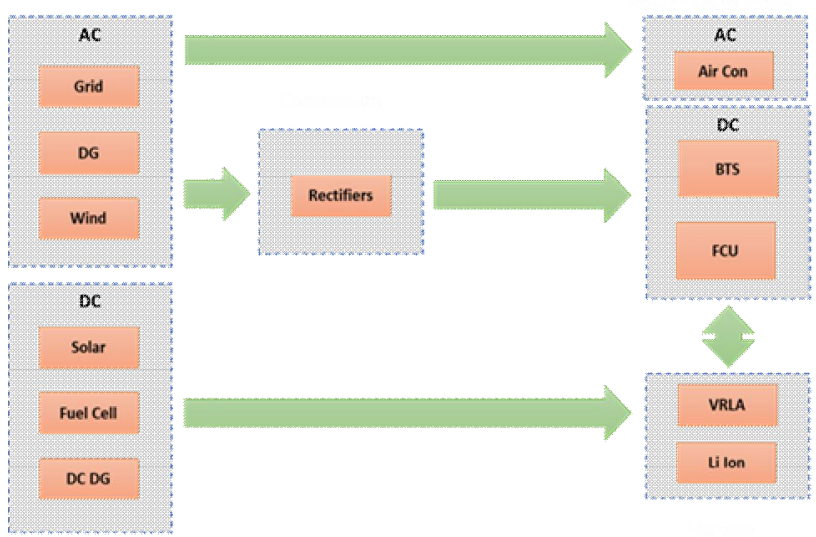

Figure 2: Block diagram of the energy system using the hybrid energy storage
The reason is that for outdoor telecom tower configuration, the generic AC common busbar that has been in the configuration for the past few decades which is the common sight at telecom towers around the world. Figure 3 shows the CAPEX and OPEX distribution costs for hybrid battery storage.

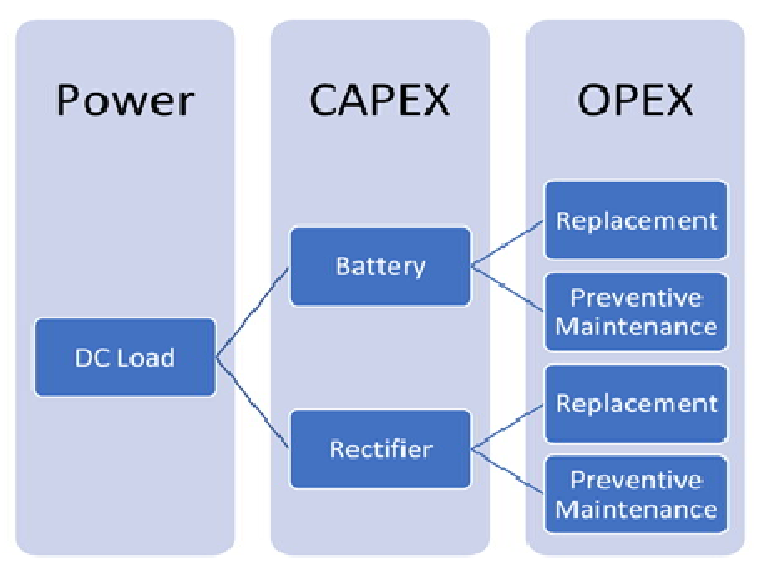

Figure 3: CAPEX and OPEX distribution for the hybrid battery storage.

\section{RESULTS AND ANALYSIS}

The parameters that we considered in our simulation are given in Table 2. Based on these parameters, we have determined the cost summary of total cash flow and the cash flow shows the year by year cash flows for both, the poor and bad grid scenarios. The factors considered in calculating the final cost based on the parameters given in Section 3 are explained as follows:

\section{i. Determine the Total Direct Current (DC) Power (BTS+Tx+ cabinet) in Watts}

ii. Decide backup time (Hrs) to produce battery capacity (Ah) with the battery cycle per day and lifetime in years

iii. Determine the cost inputs (battery, installation, cabinet/shelter and rectifier)

iv. Cost maintenance to include preventive maintenance and part replacement

v. Sites condition whether it is a poor grid or bad grid in addition to the criticality of the sites

Further cost comparison has been made with other hybrid energy storage (battery) ratios with purely lead-acid battery and purely lithium-ion battery spread over 10 years. The dependency on diesel generator as the main source of power supply already lead towards the increase of carbon emission and not so efficient power supply compared to the utility grid availability with fewer losses. 


\subsection{Cost comparison for hybrid batteries on a poor grid}

Figure 5 shows the poor grid in terms of cost comparison for 8 battery backup hours without DG (hybrid using VRLA $12 \mathrm{~V})$. We can observe that the $4 / 96$ hybrid configuration has the lowest CAPEX cost among other hybrid configurations and also other battery types namely the VRLA $12 \mathrm{~V}$ and $0 / 100$ $12 \mathrm{~V}$ with replacement cost being considered OPEX. The system with the lithium-ion battery has the highest cost and using VRLA is cheaper. The reason for this is due to the longer lifecycle for the lithium-ion battery as compared to the lead-acid battery which is much lesser in terms of the number of cycles per day, battery lifecycle and the CAPEX plus OPEX cost for 10 years of the evaluation period.

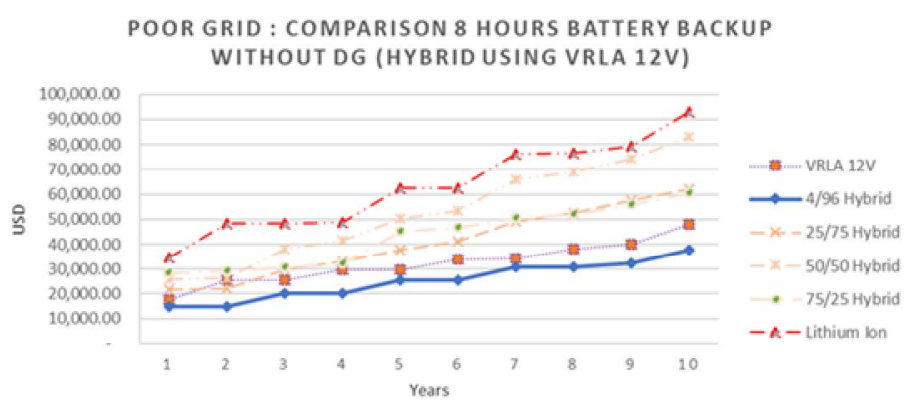

Figure 5: Poor Grid: Cost comparison 8 hours battery backup without DG (hybrid using VRLA 12V)

\subsection{Cost comparison for hybrid batteries on a bad grid}

Figure 6 compares the costs using different types of batteries for 16 battery backup hours without DG (hybrid using VRLA 12V). It is found that the battery with $4 / 96$ hybrid configuration has the lowest CAPEX cost compared to other battery types including other hybrid configurations. The system using the lithium-ion battery has the highest cost and the lead-acid battery is cheaper. This is due to the longer lifecycle of the lithium-ion battery as compared to the lead-acid battery which has much lesser in terms of the number of cycles per day, battery lifecycle and the CAPEX plus OPEX cost for 10 years of the evaluation period.

It seems with the 16 hours of grid unavailability is already approaching an off-grid situation, and hence, in the long run, it can reduce carbon emission and cost from using an unstable grid supply (up to 8 hours per day only) to charge the batteries.

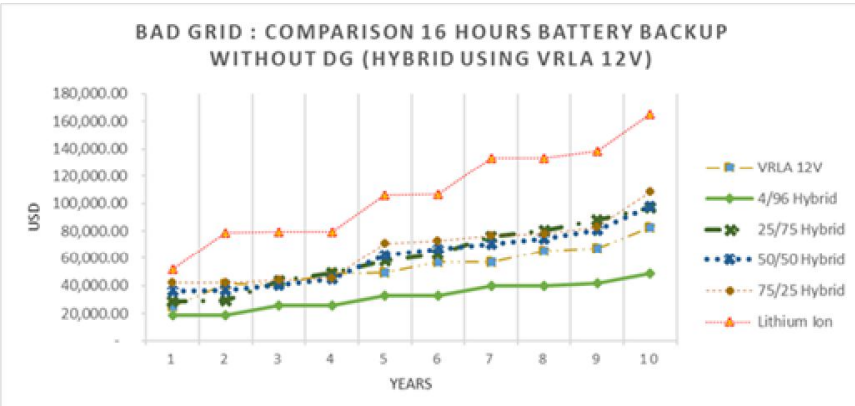

Figure 6: Bad Grid: Cost comparison 16 hours battery backup without DG (hybrid using VRLA 12V)

\section{CONCLUSION}

It has been shown that the cost of purely lithium-ion battery and the lead-acid battery is high in terms of CAPEX and OPEX for the long run of 10 years. The hybrid battery configuration has been proposed by balancing the percentage of the lithium-ion battery and lead-acid. The results have shown that with the hybrid configuration of 4/96 lowest CAPEX and OPEX costs can be achieved throughout 10 years of evaluation. Others hybrid configurations shown higher costs in terms of CAPEX and OPEX in the long run when the replacement cost of the battery is taken into account.

\section{ACKNOWLEDGEMENTS}

This work is supported by the Universiti Teknologi Malaysia under the grant Q.K130000.3556.05G14 for the publication.

\section{REFERENCES}

[1] GSMA, Green Power Design Approach and Feasibility Analysis 2014.

[2] Al-Sheikh, H. and N. Moubayed. Health status and diagnosis of batteries in renewable energy systems: An overview. in Electrical and Power Engineering (EPE), 2012 International Conference and Exposition on. 2012. IEEE

[3] Hasan, Z., H. Boostanimehr, and V.K. Bhargatableva, Green cellular networks: A survey, some research issues and challenges. IEEE Communications surveys \& tutorials, 2011. 13(4): p. 524-540.

[4] Arriagada, E., et al. A stochastic economic dispatch model with renewable energies considering demand and generation uncertainties. in PowerTech (POWERTECH), 2013 IEEE Grenoble. 2013. IEEE.

[5] Ghiassi-Farrokhfal, Y., et al., Solar power shaping: An analytical approach. IEEE Transactions on Sustainable Energy, 2015. 6(1): p. 162-170

[6] Karthigeyan V, Aswin M, Priyanka L, Sailesh KD, Palanisamy K, editors. A comparative study of lithium ion (LFP) to lead acid (VRLA) battery for use in telecom power system. 2017 International Conference on Computation of Power, Energy Information and Commuincation (ICCPEIC); 2017: IEEE.

[7] Malhotra A, Battke B, Beuse M, Stephan A, Schmidt T. Use cases for stationary battery technologies: A review of the literature and existing projects. Renewable and Sustainable Energy Reviews. 2016;56:705-21.

[8] Brunarie J, Billard A-M, Lansburg S, Belle M, editors. Lithium-ion (Li-ion) battery technology evolves to serve an extended range of telecom applications. Telecommunications Energy Conference (INTELEC), 2011 IEEE 33rd International; 2011: IEEE.

[9] Radwan AaH, H.S., . Does multi-hop communication extend the battery life of mobile terminals?. . In IEEE Globecom 2006 2006, November. :(pp. 1-5). IEEE. 
[10] Manwell JF, McGowan JG. Lead acid battery storage model for hybrid energy systems. Solar Energy. 1993;50(5):399-405.

[11] Nadeem, F., et al., Comparative review of energy storage systems, their roles, and impacts on future power systems. IEEE Access, 2018. 7: p. 4555-4585.

[12] Alsharif, M.H., R. Nordin, and M. Ismail, Green wireless network optimisation strategies within smart grid environments for Long Term Evolution (LTE) cellular networks in Malaysia. Renewable energy, 2016. 85: p. 157-170.

[13] Alsharif, M.H., R. Nordin, and M. Ismail, Energy optimisation of hybrid off-grid system for remote telecommunication base station deployment in Malaysia. EURASIP Journal on Wireless Communications and Networking, 2015. 2015(1): p. 64.

[14] Hossain, M., S. Mekhilef, and L. Olatomiwa, Performance evaluation of a stand-alone PV-wind-diesel-battery hybrid system feasible for a large resort center in South China Sea, Malaysia. Sustainable cities and society, 2017. 28: p. 358-366.

[15] Halabi, L.M., et al., Performance analysis of hybrid PV/diesel/battery system using HOMER: A case study Sabah, Malaysia. Energy Conversion and Management, 2017. 144: p. 322-339.

[16] Keshan, H., J. Thornburg, and T.S. Ustun, Comparison of lead-acid and lithium ion batteries for stationary storage in off-grid energy systems. 4th IET Clean Energy and Technology Conference (CEAT 2016). 2016.

[17] Alsharif, M., J. Kim, and J. Kim, Green and sustainable cellular base stations: An overview and future research directions. Energies, 2017. 10(5): p. 587.

[18] Ahmad, J, Musirin, I, Zamani, MKM, Mustaffa, SAS, Aminuddin, N, Shaaya, SA \& Suyono, H 2019, 'Evolutionary programming based technique for plug-in-hybrid electric vehicle charging system', International Journal of Advanced Trends in Computer Science and Engineering, vol. 8, no. 1.3 S1, 73, pp. 425-430 [19] Mansor, NN, Shaaya, SA, Musirin, I, Hannoon, NS, Mohamed, Z \& Zamani, MKM 2019, 'Embedded flower pollination evolutionary programming based technique for voltage stability enhancement with distributed generation installation', International Journal of Advanced Trends in Computer Science and Engineering, vol. 8, no. 1.3 S1, 68, pp. 387-393.

[20] Adnan, NA, Mansor, MH, Roslan, N, Musirin, I, Khader, PSA, Kamil, K, Jelani, S \& Zuhdi, AWM 2019, 'Multi-objective evolutionary programming for solving economic dispatch problem', International Journal of Advanced Trends in Computer Science and Engineering, vol. 8, no. 1.6 Special Issue, 44, pp. 296-302 